\title{
The antibacterial effect of herbal alternatives, Triphala and Turmeric, on Enterococcus faecalis
}

\section{- an in vitro study}

SADJ July 2019, Vol. 74 No. 6 p293 - p298

R Brar' ${ }^{1}$, M Goel $^{2}$, KS Arora ${ }^{3}$, KD Gupta ${ }^{4}$, PA Sethi' ${ }^{5}$, H Mankel $^{6}$

\section{ABSTRACT}

\section{Introduction}

Disinfection and shaping of the canal with a combination of chemical agents and endodontic instruments play important roles in the success of endodontic therapy. Root canal irrigants aid in achieving disinfection in canal systems inaccessible to biomechanical preparation.

A wide variety of synthetic irrigants are available today but some may be ineffective, and there may be safety concerns and side effects. Herbal alternatives may be advantageous.

\section{Author affiliations:}

1. Rubaab Brar: MDS, Senior Lecturer, Department of Paedodontics and Preventive Dentistry, Daswani Dental College \& Research Centre, Kota, Rajasthan, India.

ORCID Number: 0000-0001-5600-472X

2. Manish Goel: MDS, Prof. \& Head. Department of Paedodontics and Preventive Dentistry, Daswani Dental College \& Research Centre, Kota, Rajasthan, India.

ORCID Number: 0000-0001-8832-8147

3. Karandeep S Arora: MDS, Reader, Department of Oral Medicine \& Radiology, M. M. College of Dental Sciences and Research, Mullana, Ambala, Haryana, India.

ORCID Number: 0000-0003-1753-2305

4. Kapil D Gupta: MDS, Reader, Department of Pedodontics and Preventive Dentistry, Daswani Dental College \& Research Centre, Kota, Rajasthan, India.

ORCID Number: 0000-0002-8909-4124

5. Pooja A Sethi: MDS, Reader, Department of Pedodontics and Preventive Dentistry, M. M. College of Dental Sciences and Research, Mullana, Ambala, Haryana, India ORCID Number: 0000-0001-7280-505X

6. Hemant Mankel: MDS, Senior Lecturer, Department of Pedodontics and Preventive Dentistry, Shri. Yashwantrao Chavan Memoria Medical \& Rural Development Foundation's Dental College \& Hospital, Ahmednagar, Maharashtra, India.

ORCID Number: 0000-0002-6226-9836

Corresponding author: Karandeep S Arora

House No. 1078, Sector 19-B, Chandigarh (UT) - 160019

Tel: +917597559999

Email: drkaranarora@yahoo.com

Author contributions:

1. Rubaab Brar: Principal investigator, protocol, discussion and proof reading $-30 \%$

2. Manish Goel: Secondary investigator, protocol, discussion and proof reading - $20 \%$

3. Karandeep S Arora: Review of literature, manuscript preparation and proof reading - $10 \%$

4. Kapil D Gupta: Protocol, method, review of literature, discussion and proof reading - 15\%

5. Pooja A Sethi: Protocol, method and proof reading - 15\%

6. Hemant Mankel: Method and proof reading - $10 \%$
Aims and objectives

To evaluate the antibacterial properties of herbal extracts, namely turmeric and triphala as irrigants during endodontic treatment in comparison with the conventional irrigating solutions.

\section{Materials and method}

Agar well diffusion assay and MIC methods were used to determine the efficacy of the experimental irrigant in removing $E$. faecalis. The difference between groups was statistically analysed.

Result

2\% chlorhexidine showed the highest zone of inhibition against $E$. faecalis followed by triphala. There was no significant difference between triphala and turmeric but triphala showed more inhibition effect against $E$. faecalis because of chelating properties.

\section{Conclusion}

Chlorhexidine has significant antimicrobial efficacy against E. faecalis. Considerable reduction in growth of E. faecalis was seen in the herbal extract groups and considering their non-toxic nature and other physiological benefits, further studies are warranted.

\section{Keywords}

Herbal irrigants, E. faecalis, chlorhexidine.

\section{INTRODUCTION}

The goal of endodontic therapy is the removal of all vital or necrotic tissue, microorganisms, and microbial by-products from the root canal system. This may be achieved through chemo-mechanical debridement of the root canal.

The complex nature of the root canal complex and the presence of many inaccessible areas requires a combination of mechanical instrumentation and irrigation to decrease the amount of bacteria/microorganisms in the system. ${ }^{2}$

E. faecalis is an enteric facultative gram positive bacterium which can grow independently in the root canal. ${ }^{2}$ It is the most commonly isolated species from the root canals of the teeth, especially those with failed endodontic treatment. ${ }^{3,4}$ 
The bacterium possesses certain virulence factors such as lytic enzymes, cytolysin, pheromones, and lipotechoic acid ${ }^{5,6}$ which suppress the action of lymphocytes, potentially contributing to endodontic failure. ${ }^{7}$

In this modern era of dentistry, we are looking towards herbal alternatives. Herbal medicines are drugs of plant origin which are used to attain or maintain a condition of good health and to treat diseases. ${ }^{8}$

It has been known for thousands of years that extracts of plant origin have therapeutic properties, and it has been found that natural plant extracts could be used as effective endodontic irrigants. ${ }^{9}$

Some of the commonly used antibacterial agents are associated with increased antibiotic resistance and toxic and harmful side effects. There is a need for alternative agents which are affordable, non-toxic and effective. ${ }^{9}$

Traditional medicine is known to be fertile ground for the sourcing of modern medicines. ${ }^{10}$ Medicines in that category are turmeric and triphala. ${ }^{11}$ Keeping in view the advantages of using natural irrigants, the present research was undertaken to evaluate the antibacterial properties of herbal extracts, namely turmeric and triphala, as irrigants during endodontic treatment, compared with conventional irrigating solutions.

\section{MATERIALS AND METHODS}

The study was conducted in Department of Microbiology. The samples were divided into a study group and a control group. Turmeric and triphala were used in the study group, whilst in the control group, chlorhexidine served as the positive control and saline as the negative control.

The bacterial stain used to identify $E$. faecalis was MTCC 439 (Microbial Type Culture Collection and Gene Bank, Chandigarh (UT), India). The analysis was carried out using the Agar well diffusion assay method. ${ }^{12}$ The size of the sample to be used in the study was determined after consultation with statistician.

\section{Preparation of aqueous solution of Turmeric}

The Curcuma longa rhizomes were washed with distilled water and patted dry. They were then cut into pieces and completely dried in an oven by a tray drying process at a temperature of $40 \pm 5^{\circ} \mathrm{C}$ for a period of about 7-10 days till they were moisture-free.

The pieces were ground to form a coarse powder which was then placed in a large glass chamber into which $80 \mathrm{ml}$ of sterile distilled water was added to prepare the aqueous extract.

The glass chamber was closed with a glass lid to prevent evaporation of the menstruum and the chamber was allowed to stand for seven days with occasional stirring of the contents. ${ }^{12}$

The liquid was then strained and the solid residue, called "marc", was pressed to recover as much solu- tion as possible. The strained and expressed liquids thus obtained were mixed and clarified by filtration. Pure turmeric extract was taken and mixed with distilled water. (Turmeric preparation was $6.4 \mathrm{gms}$ in $80 \mathrm{ml}$ of distilled water).

\section{Preparation of aqueous solution of Triphala}

Ripe fruits of Terminalia chebula, Terminalia bellirica and Embellica officinalis were collected dried and powdered.

$25 \mathrm{~g}$ of the powder of each of the three fruits were separately passed through an $80 \#$ sieve and then mixed together in equal proportions to produce uniformly blended triphala churna.

This powder was then mixed with distilled water and allowed to stand for seven days in a glass chamber, with occasional stirring. (Triphala preparation was $20 \mathrm{gms}$ in $80 \mathrm{ml}$ of distilled water).

\section{Agar Well Diffusion Assay method}

The bacterium under test was E. faecalis (MTCC 439). Pure E. faecalis was grown on blood infusion agar plates. The micro-organisms were inoculated into tubes containing $5 \mathrm{~mL} 0.9 \%$ sterile saline solution. The suspension was adjusted by using McFarland tubes to match the turbidity to $1.5 \times 108 \mathrm{cfu} / \mathrm{mL}$. The blood infusion agar plates were flooded with the test suspension.

Then four wells $(4 \mathrm{~mm}$ depth $\times 6 \mathrm{~mm}$ diameter) were cut in the agar, one for each test irrigating solution (turmeric, triphala, chlorhexidine and saline). Into each well was placed $0.4 \mathrm{ml}$ of one of the irrigants, using a sterile syringe. ${ }^{2}$

The plates were then incubated at $37^{\circ} \mathrm{C}$ under appropriate atmospheric conditions $\left(80 \% \mathrm{~N}_{2}, 10 \% \mathrm{CO}_{2}, 10 \%\right.$ $\mathrm{H}_{2}$ ) for seven days under anaerobic conditions in a $\mathrm{CO}_{2}$ incubator. The diameters of the zones of inhibition of bacterial growth around the wells containing the test substances were recorded after the period of incubation.

The inhibitory zone was determined in millimetres by measuring the shortest distance between the outer margin of the well and initial microbial growth, a method previously established. ${ }^{12}$ Each experiment was performed six times and the means and standard deviations of the measurements of the inhibitory zones were calculated.

\begin{tabular}{l|c|c|c|}
\hline \multicolumn{1}{|c|}{ Table 1. Mean and standard deviation of zone of inhibition. } \\
\hline \multicolumn{1}{|c|}{ Materials } & $\begin{array}{c}\text { Sample } \\
\text { number }\end{array}$ & Mean & $\begin{array}{c}\text { Standard } \\
\text { deviation }\end{array}$ \\
\hline 2\% Chlorohexidine & 30 & 32.77 & 0.38 \\
\hline Triphala & & 24.08 & 0.33 \\
\hline Turmeric & & 12.95 & 0.25 \\
\hline
\end{tabular}

\section{RESULTS}

The means and standard deviations of the dimensions of the inhibition zones for each concentration of all the preparations are presented in Table 1. 


\begin{tabular}{|c|c|c|c|c|}
\hline \multicolumn{3}{|c|}{ Groups } & $\mathbf{P}$ & $\mathbf{R}$ \\
\hline \multirow{3}{*}{$\begin{array}{l}\text { Study } \\
\text { Group }\end{array}$} & Group I & $2 \%$ CHX - Triphla & $<0.05$ & -0.399 \\
\hline & Group II & $2 \% \mathrm{CHX}$ - Turmeric & $<0.05$ & -0.035 \\
\hline & Group III & Triphla - Turmeric & $<0.05$ & -0.59 \\
\hline \multirow{3}{*}{$\begin{array}{l}\text { Control } \\
\text { Group }\end{array}$} & Group IV & $2 \% \mathrm{CHX}$ - Saline & $<0.05$ & $\infty$ \\
\hline & Group V & Triphla - Saline & $<0.05$ & $\infty$ \\
\hline & Group VI & Turmeric - Saline & $<0.05$ & $\infty$ \\
\hline
\end{tabular}

The results were tabulated using Microsoft Excel software and an independent t-test was applied for statistical analysis which was carried out using SPSS v16 software by qualified statistician. Comparison of the results is recorded in Table 2 .

Triphala was more efficacious an inhibitor than turmeric but the co-relation suggests that neither are as efficacious against $E$. faecalis as chlorhexidine.

Overall, 2\% chlorhexidine effected the largest zones of growth inhibition in the well diffusion assay. Triphala and turmeric had significant inhibitory effects on $E$. faecalis when compared with the results of the control group.

\section{DISCUSSION}

The present research compared the antibacterial properties of herbal with conventional endodontic irrigants. The agar diffusion test used in this study is useful for evaluating and comparing the in-vitro antimicrobial activities of irrigants before performing more advanced tests; many studies have used this method for evaluation of antibacterial effects of various endodontic irrigants. ${ }^{14}$

The results obtained from this test must be interpreted with caution, as this assay may not demonstrate the full clinical potential of the material being tested. The MIC test is also a research tool to determine the in-vitro activity of new medicaments and antimicrobials.

The bacterial species $E$. faecalis was selected as representing an organism commonly isolated from the root canals of teeth that have been previously root filled ${ }^{15}$ and its prevalence in such infections ranges from 24\% to $77 \% .^{7}$ There have been several studies which applied $E$. faecalis as a target micro-organism in the evaluation of the effects of antibacterial agents.

The study conducted by Somayaji et al. compared the antimicrobial efficacy of sodium hypochlorite, triphala, Withania somnifera, a combination of triphala and Withania somnifera against Enterococcus faecalis.

Sodium hypochlorite, triphala and Withania somnifera failed to eliminate bacteria completely. But, considerable reduction in growth of $E$. faecalis was seen in the herbal extract groups though none were as effective as was seen in the sodium hypochlorite group. Another study was conducted to compare the antimicrobial activity of triphala (plant-derived solution) with
$0.5 \%, 1 \%, 2.5 \%$ and $5 \%$ concentrations of sodium hypochlorite $(\mathrm{NaOCl})$ against $E$. faecalis. ${ }^{13}$ In our study, Triphala exhibited better antimicrobial activity against $E$. faecalis compared with $0.5 \%$ and $1 \%$ $\mathrm{NaOCl}(\mathrm{P}<0.05)$.

E. faecalis has ability to invade and to live within dentinal tubules and can endure prolonged periods of starvation. E. faecalis may occur alone, in pairs or in short chains, can survive harsh environments like extreme alkaline $\mathrm{pH}(9.6)$ and a temperature of $60^{\circ} \mathrm{C}$ for $30 \mathrm{~min}^{4}$

The primary objective of endodontic therapy is microbial reduction or elimination to promote healing and reestablishment of health of the periradicular tissues. ${ }^{16}$

A variety of chemicals have been introduced. Whilst the commonly used endodontic irrigants have many potentially favourable properties, they can also cause cytotoxicity, allergic reaction, hypersensitivity or immunosuppression.

According to the World Health Organization (WHO) more than $80 \%$ of the world's population relies on traditional medicine for their primary healthcare needs. Plants used in traditional medicine contain a wide range of ingredients which are used to treat chronic as well as infectious diseases. ${ }^{16}$

Many drugs used in allopathic medicine have their origin in medicinal plants and traditional healers have relied on plant parts as folklore medicine since time immemorial.

Herbal products have a wide range of application in dentistry, such as: anticaries activity; root canal irrigants; anti-collagenase activity; anti-microbial and anti-oxidant effects and as a mouth rise. The most commonly used herbal products are turmeric and triphala. ${ }^{17}$

Turmeric appears to derive from the Latin: terra merita (merited earth) or turmeryte (Curcuma longa) and belongs to the ginger (Zingiberaceae) family. ${ }^{11}$ Curcumin, a yellow colored phenolic pigment, is the most important fraction responsible for the biological activities of turmeric.

The product has a wide spectrum of therapeutic effects such as anti-inflammatory, antibacterial, antiviral, antifungal, anti-diabetic and anti-coagulant actions, while it also acts as an antioxidant and astringent. Curcumin has been shown to kill several pathogenic bacteria that can cause infections and skin diseases.

Triphala is a well known ayurvedic herbal formulation consisting of the dried and powdered fruits of three medicinal plants, namely Terminalia bellerica, Terminalia chebula and Emblica officinalis with tannic acid being its principal constituent.

Other chemical constituents of triphala include Quinones, Flavones, Flavonoids, Gallic and Vitamin C. It has long been used in Indian traditional medicine (Indian system of medicine, ISM), for the treatment of headaches, constipation and hepatic disorders. 
Initial studies have shown bacteriostatic or bactericidal effects of tannic acid on gram-positive and gramnegative pathogens although the preparation is not as effective as is the chlorhexidine group. Compared with commonly used root canal irrigants, it is safe and is composed of compounds with appropriate physiologic effects in addition to its anti-oxidative and anti-inflammatory properties.

The most important advantages of triphala include easy access, low cost, long-term stability, less toxicity and absence of microbial resistance. ${ }^{18}$ It has anti-cariogenic and thermogenic effects and can act as a probiotic.

The antibacterial property of triphala extract has been shown in the present study by the, measurement of the zone of inhibition against $E$. faecalis, as has also been demonstrated by Shakouie et al. ${ }^{17}$

The study found turmeric to be the most effective herbal product when used as a root canal irrigant. However, this was an in vitro investigation which may not have demonstrated the full clinical potential of a tested material. Dentin can interact with herbal endodontic irrigants and the presence of a smear layer could delay any antimicrobial effects of the solutions.

Further studies should be carried out under in vivo conditions to confirm the clinical efficacy of these herbal products as useful irrigants in endodontics.

\section{CONCLUSION}

In this study $2 \%$ Chlorhexidine $(\mathrm{CHX})$ showed maximum antibacterial activity against $E$. faecalis. Triphala and Turmeric did show antibacterial activity against the organism but at significantly reduced levels. Nevertheless, herbal alternatives as root canal irrigants might prove to be advantageous considering the several undesirable characteristics of $\mathrm{CHX}$.

The non-toxic nature and other physiological benefits of these herbal extracts warrant further studies. Further research is needed to conclusively recommend herbal solutions as root canal irrigants.

\section{References}

1. Agrawal VS, Rajesh M, Sonali K, Mukesh PA. Contemporary overview of endodontic irrigants - a review. J Dent App. 2014; 1(6): $105-15$.

2. Adl A, Shojaee NS, Motamedifar M. A comparison between the antimicrobial effects of triple antibiotic paste and calcium hydroxide against Enterococcus faecalis. Iran Endod J. 2012; 7(3): 149-55.

3. Stuart CH, Schwartz SA, Beeson TJ, Owatz CB. Enterococcus faecalis: its role in root canal treatment failure and current concepts in re-treatment. J Endod. 2006; 32: 93-8.

4. Tendolkar PM, Baghdayan AS, Shankar N. Pathogenic enterococci: New developments in the $21^{\text {st }}$ century. Cell Mol Life Sci. 2003; 60: 2622-36.

5. Rôças IN, Siqueira JF Jr, Santos KR. Association of Enterococcus faecalis with different forms of peri-radicular diseases. J Endod. 2004; 30: 315-20.

6. Figdor D, Davies JK, Sundqvist G. Starvation survival, growth and recovery of Enterococcus faecalis in human serum. Oral Microbiol Immunol. 2003; 18: 234-9.
7. Kumar $\mathrm{H}$. An in vitro evaluation of the antimicrobial efficacy of Curcuma longa, Tachyspermumammi, chlorhexidine gluconate, and calcium hydroxide on Enterococcus faecalis. J Cons Dent. 2013; 16(2): 144-7.

8. Subasree S, Murthy Kumar K, Sripradha S. Effects of turmeric on oral health: an overview. International $\mathrm{J}$ Pharma Sci Health Care. 2014; 2(4): 6-14.

9. Kamat S, Rajeev K, Saraf P. Role of herbs in endodontics. An update, Endodontology. 2014; 26(1): 98-102.

10. Corson TW, Crews CM. Molecular understanding and modern application of traditional medicines: triumphs and trials. Cell 2007; 130(5): 769-74.

11. Praveen SK. Mandroli, Bhat K. An in-vitro evaluation of antibacterial activity of Curcumin against common endodontic bacteria. J App Pharma Sci. 2013; 3(10): 106-8.

12. Hegde V, Kesaria DP. Comparative evaluation of antimicrobial activity of neem, propolis, turmeric, liquorice and sodium hypochlorite as root canal irrigants against E. faecalis and C. albicans - An in vitro study. Endodontology. 2013; 25(2): 38-45.

13. Somayaji KS, Ballal NV, Shobha KL, Mohandas Rao KG. Comparison of antimicrobial efficacy of triphala, Withania somnifera and sodium hypochlorite against Enterococcus faecalis biofilm-an in vitro study. Int J Pharm Sci; 6(2): 808-81.

14. Asgary S, Kamrani FA, Taheri S. Evaluation of antimicrobial effect of MTA, calcium hydroxide, and CEM cement. Iran Endod J. 2007; 2(3): 105-9.

15. Siqueira JF Jr. Aetiology of root canal treatment failure: why well-treated teeth can fail. Int Endod J. 2001; 34(1): 1-10.

16. Hegde MN, Shetty S, Yelapure M, Patil A. Evaluation of antimicrobial activity of aqueous and hydro-alcoholic Curcuma longa extracts against endodontic pathogens. J Pharma. 2012; 2(2): 192-8.

17. Shakouie S, Eskandarinezhad M, Gasemi N, Milani AS, Samieia M. An in-vitro comparison of the antibacterial efficacy of Triphala with different concentrations of sodium hypochlorite. Iran Endod J. 2014; 9(4): 287-9.

18. Prakash S, Shelke AU. Role of Triphala in dentistry. J Indian Soc Periodontol. 2014; 18: 132-5. 